\title{
Burnout and Depression among Medical Students at Historically Black Colleges and Universities (HBCU) Hospital System
}

Etesam Amir, Suneeta Kumari, Uradu Olivetta and Malik Mansoor

Howard University Hospital, Department of Psychiatry and Behavioral Sciences, Washington, DC 20059, USA

Abstract

Psychological distress and chronic exposure to high levels of stress during medical school can result in a "burnout syndrome" with the potential for multiple detrimental consequences. Burnout syndrome develops as the sequence of emotional exhaustion, followed by depersonalization as a coping mechanism, and which finally manifests itself as feelings of professional dissatisfaction and anguish. If burnout continues into residency and later into medical practice, it will affect the physician's functioning and quality of life. Interventions targeting unsuccessful coping strategies and complications related to burnout, may offer an opportunity to improve medical student well-being and mental health.

In the field of medicine, physicians and residents have been the focus of research on burnout, but little investigation has been done on medical students. This research project is being conducted to assess the prevalence of burnout among third year medical students at Howard University College of Medicine, a Historically Black College and University (HBCU) hospital system. This study is being conducted for the benefit and well-being of students; we hope it will better enable us to devise effective interventions to address and prevent burnout in the future studies, which will result in positive outcomes for our future resident physicians.

\section{Introduction}

Burnout syndrome was first described in the 1970's work related constellation of symptoms that usually occurs in individuals without any prior history of psychological and psychiatric disorders. In many cases burnout is triggered by a discrepancy between the expectations and ideals of the employee and he actual requirements of their position [1]. The risk factors for burnout can be divided into two categories(1) Individual related risk factors such as having poor self-esteem, maladaptive coping mechanism, unrealistically high expectations, and financial issues. (2) Organizational risk factors- conflict with coworkers, heavy workload, rapid institutional change, diminished resources and variability in work schedule. Burnout is a growing problem and it rose in nearly all specialities and it has high prevalence. According to American Psychiatric Association as estimated $40 \%$ of psychiatrists have professional burnout. Emergency medicine had the highest greater than $60 \%$. Among General practitioners the prevalence rate is $40 \%$ to $60 \%[2,3]$.

Research suggests that medical school burnout is estimated around $50 \%$, about the same prevalence as in residents and physicians [4]. Consequences of medical student burnout, in addition to high levels of perceived stress and emotional distress, include self-reported cheating and dishonest clinical behaviors, increased symptoms of depression, and the increased likelihood of suicidal ideation $[6,2,5]$.

In 2011, the prevalence of burnout among practicing physicians in the United States was estimated at 54\% [3] with several contributing factors ranging from excessive workload to conflicts with worklife integration. This chronic condition not only impacts physician and medical students' well-being but is also important because it is directly linked to lower patient satisfaction, longer post-discharge recovery time [6], and higher mortality ratios in hospitalized patients [2]. While the problem of physician burnout is widely recognized with diverse solutions implemented across the country, research into resident burnout is less, and there has been almost no research into medical student burnout.

\section{Objective}

To evaluate the prevalence of burnout and associated factors with the development of burn out among third year medical students at HBCU.

\section{Methods}

This study is approved by Howard University IRB. This is a crosssectional quantitative study Conducted at the Howard University Hospital from March 2018 to June 2018. The Howard University Hospital was built on the foundation of Freedmen's Hospital and Asylum, which cared for freed, disabled, and aged blacks. In 1868, after the Civil War, Freedmen's Hospital became the teaching hospital of Howard University Medical School. In 1909, a new 278-bed Freedmen's Hospital was erected. In 1975, the current and modern University Hospital was opened. For many years, Howard University was the only Carnegie I research intensive institution and has trained more African Americans with professional or doctoral degrees than any other institution.

The study was performed in accordance with the international ethical standards of the Declaration of Helsinki. Medical students indicated their agreement to participate in the study via the electronic informed consent included in the electronic survey form. In order to ensure and facilitate the completion of the questionnaires and increase the confidentiality of the data, we chose to collect online questionnaire

"Corresponding Author: Dr. Suneeta Kumari, Howard University Hospital, Department of Psychiatry and Behavioral Sciences, Washington, DC 20059, USA; E-mail: suneeta.kumari@howard.edu

Citation: Amir E, Kumari S, Olivetta U, Mansoor M (2018) Burnout and Depression among Medical Students at Historically Black Colleges and Universities (HBCU) Hospital System. Int J Psychol Behav Anal 4: 151. doi: https://doi. org/10.15344/2455-3867/2018/151

Copyright: (C) 2018 Kumari et al. This is an open-access article distributed under the terms of the Creative Commons Attribution License, which permits unrestricted use, distribution, and reproduction in any medium, provided the original author and source are credited. 
Citation: Amir E, Kumari S, Olivetta U, Mansoor M (2018) Burnout and Depression among Medical Students at Historically Black Colleges and Universities (HBCU) Hospital System. Int J Psychol Behav Anal 4: 151. doi: https://doi.org/10.15344/2455-3867/2018/151

Page 2 of 3

responses using the Survey Monkey program, which was obtained legally from the registration on the site (https://pt.surveymonkey. com).

\section{Instruments}

The questionnaire was designed to take on average of 15 minutes to complete and contained the following instruments.

\section{Maslach burnout inventory (MBI)}

22 item self-administered anonymous online survey which was distributed to all third-year medical students at $\mathrm{HUH}$ in Washington DC. The survey contains standardized questions from Maslach Burnout Inventory (MBI) to screen for the level of burnout in students, in combination with demographic and brief psychiatric history questions from the participants. The MBI instrument containing 15 unique items for the evaluation of burnout among medical students.

MBI analyzes burnout in three sub-scales on a continuum: Emotional Exhaustion, Depersonalization, and Personal Accomplishments. It divides the level of burnout into low, moderate and high for each of the three sub-scales. Higher scores on the Emotional Exhaustion and Depersonalization corresponds to higher levels of burnout and on the other hand lower scores in the Personal Accomplishments indicates a more severe burnout. The specific score ranges are reflected in the chart below.

\begin{tabular}{|l|l|l|l|}
\hline & Low & Moderate & High \\
\hline Emotional Exhaustion & $0-16$ & $17-26$ & $27+$ \\
\hline Depersonalization & $0-6$ & $7-12$ & $13+$ \\
\hline Personal Accomplishment & $39+$ & $32-38$ & $0-31$ \\
\hline
\end{tabular}

A total of 105 third year medical students were invited to participate via a Howard University School of Medicine listserv and 61 people responded to the survey (participation rate of 58 percent).

\section{Results}

The level of burnout in HUH Third Year Medical students are as follows:

\begin{tabular}{|l|l|l|}
\hline & HUH-3rd years & Level \\
\hline Emotional Exhaustion & 17.754 & Moderate \\
\hline Depersonalization & 15.79 & High \\
\hline Personal Accomplishments & 26.31 & High \\
\hline
\end{tabular}

Table 2:

More specifically the number of respondents in each level of burnout in each category is being reproduced in the table below.

\begin{tabular}{|l|l|l|l|}
\hline & Low & Moderate & High \\
\hline Emotional Exhaustion & 23 & 33 & 5 \\
\hline Percent (\%) & 37.70 & 54.10 & 8.20 \\
\hline Depersonalization & 9 & 14 & 38 \\
\hline Percent (\%) & 14.75 & 22.95 & 62.30 \\
\hline Personal Accomplishments & 0 & 11 & 50 \\
\hline Percent (\%) & 0 & 18.03 & 82.00 \\
\hline Table 3: & \multicolumn{3}{|l}{} \\
\hline
\end{tabular}

Int J Psychol Behav Anal

ISSN: 2456-3501
Our data suggests that most of the respondents show moderate and high levels of burnout. This study should act as a caution regarding the future physicians who are currently suffering from moderate to high levels of perceived burnout. If appropriate steps are not taken to intervene, the future negative impacts of burnout would be inevitable as described above.

\section{Discussion}

In this study, we investigated severity of burnout among third year medical students. Our data suggests that more than $60 \%$ of participants suffer from moderate to high levels of emotional exhaustion, above $80 \%$ indicated depersonalization at the same severity level and almost all the participants are not satisfied with their personal accomplishments which is leading to a burnout prevalence of above 70 percent in our participants. Our data suggests no difference in prevalence of burnout based on gender; however, prior diagnosis of a psychiatric illness was a major contributor to burnout levels in the severe level.

Physician burnout may be related to chronic workplace stressors starting as early as the first year of medical school, with onset of burnout arising from mental and physical exhaustion owing to the demanding medical curriculum, increasing time constraints, and harsh learning climates [3]. Calls for changes to medical curricula to address psychological distress have been made, but little is known about how curricula could be reformed and the expected outcome, despite information regarding the interference of burnout with the teaching/learning process. Other contributors to burnout are students' self-perception of health, optimism and motivation regarding their studies, constant exposure to sick patients and death, and exhausting study routines [1].

Further, there are several negative consequences of burn out and depression such as difficulty relationships with co-workers, poor judgment or errors in patient care. Poor quality of care delivered to patients resulting in poor health outcome. Burnout also leads to lower retention of healthcare providers.

In order to minimize the negative consequences of depression and burnout syndrome, protective strategies have been reported in the literature such as physical activity, adequate sleep, psychosocial support and better learning environment [7]. It is crucial to develop strategies to prevent burnout and depression among students through curricular flexibility, better educational strategies, and schedule management are some of the promising ways to reduce burnout. Further, academic institutions should also consider the implementation of faculty development programs to optimize the learning environment [2].

Two key maladaptive coping strategies, avoidance and decreased engagement in values-based behavior, has been recognized to have a significant detrimental effect on medical students' emotional well-being [1]. Strategies in managing these detrimental behaviors have been suggested in an effort to control the burnout level in this group. Avoidance is an attempt to prevent exposure to unwanted experiences and that provides immediate relief and satisfaction. However, this can also result in abandoning the medical student's life goals. Dissatisfaction with life correlates with burnout in a variety of samples of health care providers [5].

The second factor, decreased engagement in values-based behavior, occurs when students engage in maladaptive actions even in the presence of dissatisfactory internal experiences. For example, students 
Citation: Amir E, Kumari S, Olivetta U, Mansoor M (2018) Burnout and Depression among Medical Students at Historically Black Colleges and Universities (HBCU) Hospital System. Int J Psychol Behav Anal 4: 151. doi: https://doi.org/10.15344/2455-3867/2018/151

Page 3 of 3

will over-study for exams thereby jeopardizing their relationships with friends and family members.

Burnout and depression can potentially be minimized if students are able to live in accordance with his or her values, despite stressors. This will provide opportunities to reconnect with the surrounding environment and benefit from social support and positive reinforcements and this will result in positive outcomes, including decreased psychological distress, better adjustment, and improved quality of life [8].

Contributors outside the school environment, and family-related stressors, have relatively insignificant influence on the development of burnout and stressors induced by the intense study, the frequent testing that takes place, and the continuous interaction with sick patients and death. If students spent more time outside of the hospital setting, this could potentially be protective against burnout. Family closeness and interactions have been reported as protective factor that lower stress levels and promotes happiness [8].

\section{Limitations of The Study}

This study has some limitations. First, the study was conducted in a single private Historically Black College and University with smaller sample size which diminishes the generalization power of the study. This study conducted among students who came from different schools with unknown previous impact of burnout, therefore a longitudinal assessment of these students would be a more appropriate approach. Further, the lack of a group of non-medical students as a control and the lack of participation of other students is also a limiting factor and it impacts overall results of the survey.

\section{Conclusion}

In summary, medical student burnout is common, and additional more effort should be made to study its prevalence amongst medical students, its racial and socioeconomic effects, and subsequent training that will effectively address the emotional, mental, and physical challenges inherent to medical school. Given that burnout has been significantly associated with suboptimal patient care, interventions that improve medical student mental health, and subsequently physician mental health, have the potential to improve the quality of healthcare and patient outcomes in the long term.

\section{Competing Interests}

The authors declare that they have no competing interests.

\section{References}

1. Boni RAdS, Paiva CE, de Oliveira MA, Lucchetti G, Fregnani JHTG, et al. (2018) Burnout among medical students during the first years of undergraduate school: Prevalence and associated factors. PLoS ONE 13: e0191746.

2. Dyrbye LN, Massie FS, Eacker A, et al. (2010) Relationship between Burnout and Professional Conduct and Attitudes Among US Medical Students. JAMA 304: 1173-1180.

3. Dyrbye LN, Thomas MR, Harper W, Massie FS Jr, Power DV, et al. (2009) The learning environment and medical student burnout: A multicentre study. Med Educ 43: 274-282.

4. Dyrbye LN, Thomas MR, Massie FS, Power DV, Eacker A, et al. (2008) Burnout and Suicidal Ideation among U.S. Medical Students. Ann Intern Med 149: 334-341.
5. Dyrbye LN, West CP, Satele D, Boone S, Tan L, et al. (2014) Burnout Among U.S. Medical Students, Residents, and Early Career Physicians Relative to the General U.S. Population. Acad Med 89: 443-451.

6. Halbesleben JR, Rathert C (2008) Linking physician burnout and patient outcomes: Exploring the dyadic relationship between physicians and patients. Health Care Manage Rev 33: 29-39.

7. Heinen I, Bullinger M, Kocalevent RD (2017) Perceived stress in first year medical students - associations with personal resources and emotional distress. BMC Med Educ 17: 4.

8. Kroska EB, Calarge C, O'Hara MW, Deumic E, Dindo L, et al. (2017). Burnout and depression in medical students: Relations with avoidance and disengagement. Journal of Contextual Behavioral Science 6: 404-408.

9. Shanafelt TD, Hasan O, Dyrbye LN, Sinsky C, Satele D, et al. (2015) Changes in Burnout and Satisfaction With Work-Life Balance in Physicians and the General US Working Population Between 2011 and 2014. Mayo Clin Proc 90: 1600-1613.

10. Wallace JE, Lemaire JB, Ghali WA (2009) Physician wellness: A missing quality indicator. Lancet 374: 1714-1721. 